\section{Holding back on dangerous play}

\section{Lawrence Freedman}

Superpower Games: Applying Game Theory to Superpower Conflict. By Steven J. Brams. Yale University Press:1985. Pp.176. Hbk \$31.50, £22.50; pbk \$9.75, £6.95.

THERE was a time when game theory was all the rage in the strategic studies community This was the "golden age" of strategic studies - the late 1950s and early 1960 s - when it was fresh with new ideas and insights on how best to deal with the nuclear dilemmas that were perplexing policy-makers.

Game theory was ideal in two ways. First, it offered a methodology of some sophistication with which to challenge the traditional approaches to strategic issues based on history and politics and military experience All of these were now deemed to be irrelevant in the nuclear age Second, the assumptions behind game theory fitted in with the predispositions of the new generation of strategists. It was not that they saw superpower conflict as a "game"; the term only really referred to the idea of structured situations in which the ability of either "player" to achieve his best outcome depended on decisions taken by the other.

Superpower conflict at the time seemed to be suited to game theory for three reasons. First it involved two sides who were deeply antagonistic and likely to be so for the foreseeable future: there was no risk of the game dissolving in an outbreak of peace and harmony. Second despite this, the antagonism was incomplete There was some common ground - to take the most obvious, a mutual interest in the avoidance of an outbreak of nuclear war. Third, as on the one hand the two sides were engaged in a contest for power and influence in the world, while on the other a nuclear war in which both would be devastated was the most likely result of any attempt to resolve differences through military means, it was useful to have a tool for identifying the solutions that logic might lead both powers to adopt in particular types of situation If some solutions pointed to disaster then corrective action would need to be applied.

Within its limits game theory was quite valuable. It served as a means of emphasizing the extent to which superpower confrontation did not necessarily mean that one gained what the other lost (zero sum-games) but that there could be circumstances in which both won or both lost (non-zero sum games). It drew attention to the extent to which in non-zcro-sum games both sides might tend towards the best of the worst solutions (minimax). Following through the logic of certain games could illuminate aspects of the real dilemmas that the superpowers faced. But the approach did have its limits: the individual games had to be simplified in order to keep them manageable and a presumption of rationality had to be made. Moreover, the results of the games depended critically on the assumptions made as to the choices available to the two sides, and the values attached to the alternative outcomes (payoffs).

Accordingly the best exponents of game theory (notably Tom Schelling) never allowed themselves to be restricted by the theory and were often at their most effective in using it only as a starting point for a broader analysis. Those who had dabbled with it when fashionable soon lost in-

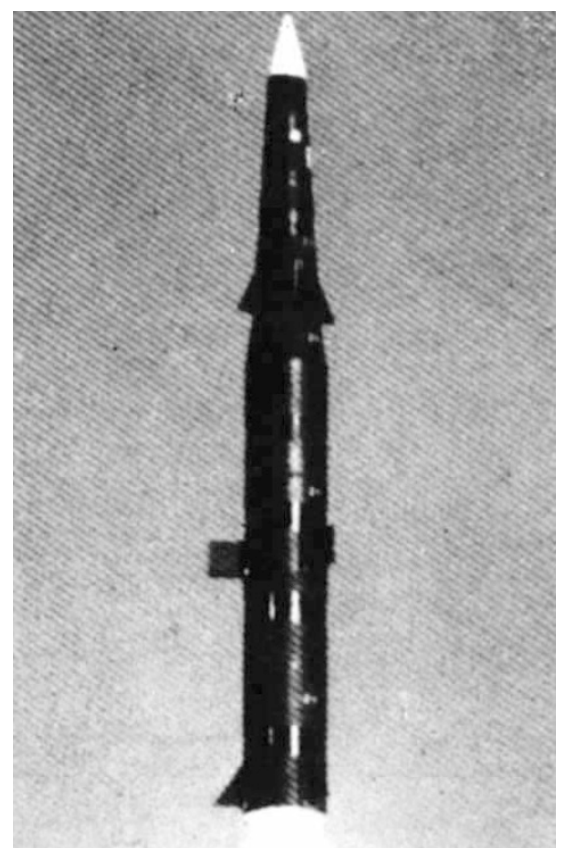

Pershing II missile - large chip in a deadly game.

terest. Nevertheless a number of scholars have persisted with the development of the technique.

Steven Brams is one such scholar who has worked hard to extend the range and applications of the basic theory. This book, which is made up of previously published articles, updated and reworked to give them some coherence, contains the results of his work. He is an unqualified believer in its continuing relevance. In the concluding chapter he states: "The evidence seems to me incontestable that game theory captures a substantial part of the logical basis and empirical reality of superpower conflict and provides a unified framework for its analysis" (p.145).

This case can be assessed by examining the quality of the analysis and then the value of the conclusions. For the first, it has to be said that Brams makes few concessions to his reader. He does not attempt to justify his methodology against the standard objections or to introduce it for a lay reader. The mathematics is hard work for those (such as myself) who are out of practice, and the argument is tight. So all that can be said, with the utmost humility, is that it seemed fine to me.

Much of the development of theory in this book constitutes an attempt to catch up with the empirical reality, and this accounts for much of the complexity of the argument. One means by which this is done is to test the theory against case studies such as the Cuban missile crisis of 1962 and the nuclear alert during the concluding stages of the 1973 Yom Kippur War. One concept of which Brams appears to be especially proud is that of "nonmyopic calculation" which essentially shows (if I have understood it correctly) how a different outcome is achieved when the belligerents are encouraged to take a long-term view and are not dominated by short-term considerations.

The question, however, is whether empirical reality is driving the theory to explain in complicated ways what might be explained more simply by more straightforward methods, or whether the theory can tell us something new. At times it is indeed illuminating but not to anything like the extent the author appears to believe.

In the end Brams suggests that the opponents act the way they do because of the "rules of the game" rather than because of anything very fundamental in the two sides' make-up. This seems to me to be going too far. It may be that the logic of the situations in which "players" find themselves influences the character of their choices, and the way those choices are made cannot be understood solely by reference to the rules of the game. Moreover, in structuring the games themselves, Brams makes some rather arbitrary judgements on the nature of the choices. For example, over Cuba, the options given for the United States are to blockade or to strike at the Cuban bases, and for the Soviet Union to retain the missiles or withdraw them. This does no justice to the actual range of choices - the United States might have done nothing; the Soviet Union might have escalated matters to take in Berlin. In the three basic issues Brams tackles - deterrence, arm-races and verification - only one dimension of the problem is addressed and the way that the problem itself is defined is controversial. On the whole the proposals at the end of the book are sensible, which gives one greater confidence in the analysis, but they are by no means wholly original and could have been arrived at by simpler methods.

In short Brams has demonstrated his skill as an exponent of games theory, and its continuing if modest value as an aid to working through the logic of superpower conflict. He has been far less successful in justifying the somewhat grandiose claims that he makes for the enterprise.

Lawrence Freedman is Professor in the Depart ment of War Studies, Kings College London (KQC), Strand, London WC2R $2 L S$, UK. 